\title{
Proof That Chronic Lyme Disease Exists
}

\author{
Daniel J. Cameron \\ Department of Medicine, Northern Westchester Hospital, Mt. Kisco, NY 10549, USA \\ Correspondence should be addressed to Daniel J. Cameron, cameron@lymeproject.com
}

Received 11 December 2009; Accepted 26 March 2010

Academic Editor: Guey Chuen Perng

Copyright ( 2010 Daniel J. Cameron. This is an open access article distributed under the Creative Commons Attribution License, which permits unrestricted use, distribution, and reproduction in any medium, provided the original work is properly cited.

\begin{abstract}
The evidence continues to mount that Chronic Lyme Disease (CLD) exists and must be addressed by the medical community if solutions are to be found. Four National Institutes of Health (NIH) trials validated the existence and severity of CLD. Despite the evidence, there are physicians who continue to deny the existence and severity of CLD, which can hinder efforts to find a solution. Recognizing CLD could facilitate efforts to avoid diagnostic delays of two years and durations of illness of 4.7 to 9 years described in the NIH trials. The risk to society of emerging antibiotic-resistant organisms should be weighed against the societal risks associated with failing to treat an emerging population saddled with CLD. The mixed long-term outcome in children could also be examined. Once we accept the evidence that CLD exists, the medical community should be able to find solutions. Medical professionals should be encouraged to examine whether: (1) innovative treatments for early LD might prevent CLD, (2) early diagnosis of CLD might result in better treatment outcomes, and (3) more effective treatment regimens can be developed for CLD patients who have had prolonged illness and an associated poor quality of life.
\end{abstract}

The evidence continues to mount that Chronic Lyme Disease (CLD) exists and must be addressed by the medical community if solutions are to be found. Thirty-four percent of a population-based, retrospective cohort study in Massachusetts were found to have arthritis or recurrent arthralgias, neurocognitive impairment, and neuropathy or myelopathy, a mean of 6 years after treatment for Lyme disease (LD) [1]. Sixty-two percent of a cohort of 215 consecutively treated LD patients in Westchester County were found to have arthralgias, arthritis, and cardiac or neurologic involvement with or without fatigue a mean of 3.2 years after treatment [2]. Klempner trials' subjects presenting with "well-documented, previously treated Lyme disease...had persistent musculoskeletal pain, neurocognitive symptoms, or dysesthesia, often associated with fatigue" and were ill during a mean of 4.7 years after onset [3]. Fallon trial subjects presenting with "well-documented Lyme disease, with at least 3 weeks of prior IV antibiotics, current positive IgG Western blot, and objective memory impairment," were ill during a mean of 9 years after onset [4]. Krupp LD subjects presented with "persistent severe fatigue at least 6 or more months after antibiotic therapy" [5].
There is also evidence that symptoms of CLD can be severe [4-8]. The Klempner trials described the quality of life for patients with posttreatment chronic Lyme disease (PTLD) as being equivalent to that of patients with congestive heart failure or osteoarthritis, and their physical impairment was "more than $0.5 \mathrm{SD}$ greater than the impairment observed in patients with type 2 diabetes or a recent myocardial infarction" [3]. Fallon et al. described pain reported by patients with Lyme encephalopathy as being "...similar to those of postsurgery patients", and their fatigue "was similar to that of patients with multiple sclerosis." Limitations in physical functioning on a quality of life scale were "comparable with those of patients with congestive heart failure" [4].

Despite the above documented evidence, the 2006 Infectious Diseases Society of America (IDSA) LD treatment guideline panel questioned the existence of CLD [9]. The IDSA panel concluded, "Considerable confusion and controversy exist over the frequency and cause of this process and even over its existence" [9]. The IDSA panel referred to chronic manifestations of LD as Post-Lyme disease syndrome (PLDS), PTLD and CLD. There are shortcomings for each term. The PLDS nomenclature implies that an active LD has been successfully treated, that any remaining symptoms 
are merely harmless vestiges of previous illness, and that the patient has been cured. The term PTLD merely implies that LD has been treated with antibiotics for 10 to 30 days. The CLD nomenclature implies that chronic manifestations of LD are present with or without evidence of active infection that cannot be reasonably explained by another illness.

There is no objective way to rule out an active infection. Lab tests that can be very helpful in confirming a clinical diagnosis of Lyme disease (such as the ELISA and Western blot tests) are not useful in determining whether the infection has been adequately treated. Common LD symptoms such as Bell's palsy, erythema migrans rash, meningitis, arthritis, or heart block, which are included in the current surveillance definitions, can be useful in "ruling in" Lyme disease, but the absence or disappearance of these symptoms cannot "rule out" an ongoing infection. A population-based, retrospective cohort study of individuals with a history of LD revealed that they were significantly more likely to have joint pain, memory impairment, and poor functional status due to pain than persons without a history of $\mathrm{LD}$, even though there were no signs of objective findings on physical examination or neurocognitive testing [10]. Two recent mouse studies revealed that spirochetes persist despite antibiotic therapy and that standard diagnostic tests are not able to detect their presence $[11,12]$. In sum, there are no clinical or laboratory markers that identify the eradication of the pathogen.

The IDSA panel also questioned the severity of CLD symptoms. The panel dismissed LD symptoms that persisted or recurred after their recommended, short-term course of treatment, stating that they were: "more related to the aches and pains of daily living rather than to either Lyme disease or a tickborne coinfection" [13]. The panel came to this conclusion despite four NIH retreatment trials that validated the severity of symptoms on 22 standardized measures of fatigue, pain, role function, psychopathology, cognition, and quality of life (QOL) [9].

Denying the existence and severity of CLD will continue to hinder the efforts to find a solution. Even in a prospective trial of LD, 10 to $16 \%$ of patients treated at the time of an erythema migrans rash remained symptomatic a mean of 30 months after treatment; the results varied depending on the duration of antibiotics treatment [14]. The actual failure rate in this prospective at 30 months is uncertain, given that $38 \%$ of the subjects were not evaluable due to poor adherence, receipt of intercurrent antibiotics, or development of a second episode of erythema migrans [14]. Patients infected with many other kinds of common bacteria-such as those that cause tuberculosis, bronchitis, or UTIs - can experience relapses after an initial course of antibiotic treatment fails or proves inadequate. Doctors routinely retreat patients who relapse in order to achieve a cure and prevent chronic symptoms. Why should patients with Lyme disease be treated differently?

The treatment failure rates could be exacerbated by diagnostic delays. Feder described treatment delays of six weeks in LD patients initially misdiagnosed with cellulitis [15]. In his trial, Fallon noted treatment delays averaging 2 years [4] without examining the causes of the delay. In my own practice, $32 \%$ of a consecutive case series of LD cases (confirmed by an ELISA and 5 or more positive bands on a IgG Western blot) had an average treatment delay of 1.8 years. [16] Of these, $60 \%$ conformed to Centers for Disease Control and Prevention (CDC) epidemiological criteria, presenting with a rash, Bell's palsy, or arthritis, yet, still had a diagnostic delay [16]. Patients in this case series were significantly more likely to fail their initial antibiotic treatment if they had delayed treatment [16]. Vrethem et al. concluded that patients treated because of neurological symptoms of LD were much more likely to present with persistent neuropsychiatric symptoms (headache, attention problems, memory difficulties, and depression) three years after treatment than a control group with erythema migrans (50\% versus $16 \%, P<.0001$ ) [17].

The diagnostic delays could reflect the failure to consider CLD in the differential diagnosis of chronic manifestations of LD. Steere did not include CLD in the differential diagnosis of patients seen in his university-based clinic. Instead, Steere diagnosed three-quarters of patients with "fibromyalgia" or "chronic fatigue syndrome" [18]. Similarly, Reid et al. did not include CLD as a diagnosis in their university LD clinic. Instead, he diagnosed these patients with "arthralgiamyalgia syndrome," primary depression, asymptomatic deer tick bites, osteoarthritis, and bursitis [16]. Hassett et al. diagnosed PTLD in patients with a history of objective evidence of LD, but withheld it from patients who lacked such a history. Instead, this group was diagnosed with "Chronic Multisymptom Illness (MUI) [19]. Their case definition for Chronic Multisymptom Illness was: " [having] at least one or more chronic symptoms from at least 2 of 3 categories of symptoms including musculoskeletal, fatigue, and mood cognition" that includes fibromyalgia, chronic fatigue syndrome, and Gulf War syndrome [19].

The risks to the individual and society of CLD have not been adequately considered [20]. As a group, CLD subjects in the four NIH trials had a $4 \%$ risk of a serious adverse event in the antibiotic treatment arms [4-6]. Yet, this risk has not been weighed against the risk CLD patients face if burdened with a long-term debilitating illness. The risk to society of emerging resistant organisms also has not been weighed against the societal risks associated with an emerging population saddled with CLD [8].

The economic burden of CLD has yet to be addressed. The mean cost estimate of CLD per patient in the US, of $\$ 16,199$ per annum in 2002 dollars [8], reflects the toll on human health and cost to society. The annual per-patient cost of CLD is substantially higher than the cost for other common chronic illnesses: \$10,911 for fibromyalgia [21], \$ 10,716 for rheumatoid arthritis [21], and $\$ 13,094$ for lupus [22]. Eighty-eight percent of the cost $(\$ 14,327)$ of Lyme disease consisted of indirect medical cost, nonmedical cost, and productivity losses. Cutting medical cost would save, at most, only $12 \%$ or $\$ 1,872$ per annum. In 2002 , the annual economic cost of LD in the US, based on the 23,000 cases reported to the CDC that year, was estimated to be $\$ 203$ million [8]. Considering that the actual number of LD cases is believed to be 10 times higher than the number of cases reported to the $\mathrm{CDC}$, the actual annual cost could be $\$ 2$ billion $[23,24]$. 
The burden of CLD is also reflected in testimony given by Connecticut's chief epidemiologist before the state's Public Health Department in 2004: "...roughly one percent of the entire population or probably 34,000 people are getting a diagnosis of Lyme Disease in Connecticut each year. . 20 to 25 percent of all families [in Connecticut] have had at least one person diagnosed with Lyme Disease ever and. ..three to five percent of all families have had someone diagnosed with Lyme Disease in the past year" [24].

No additional antibiotic trials have been planned for CLD patients despite the limitations of the Klempner and Fallon trials. Klempners' trials were limited by: (1) uncertainty over whether the initial antibiotic treatment was effective, (2) ongoing illness despite a mean of three previous treatments, (3) long onsets of illness averaging 4.7 years, (4) the poor quality of life of the subjects, and (5) small, underpowered sample sizes of 51 and 78 subjects [25]. The Fallon trial had similar limitations including: (1) uncertainty over whether the initial antibiotic treatment was effective, (2) treatment delays averaging two years, (3) onsets of illness averaging 9 years, (4) the severe pain, fatigue, psychopathology, and poor QOL of subjects, and (5) a small underpowered sample size of 37 subjects. The IDSA panel did not suggest any further clinical trials to address these limitations. In an editorial titled "Enough is Enough", which was published as a commentary on Fallon's trial, Halperin, an IDSA panel member, actually advised against further trials [26].

There is also an urgent need to address the mixed longterm outcome in children. Eleven percent of children with facial nerve palsy had persistent facial nerve palsy causing dysfunctional and cosmetic problems at 6-month followup [27]. Fourteen percent of 86 children had neurocognitive symptoms associated with or after classic manifestations of Lyme disease on followup [28]. Five of these children developed "behavioral changes, forgetfulness, declining school performance, headache or fatigue and in two cases a partial complex seizure disorder" [28]. Children with prior cranial nerve palsy have significantly more behavioral changes $(16 \%$ vs. $2 \%$ ), arthralgias and myalgias ( $21 \%$ vs. $5 \%$ ), and memory problems ( $8 \%$ vs. $1 \%)$ an average of 4 years after treatment compared to controls [29].

Once we accept the evidence that CLD exists, the medical community should be able to find solutions. Professionals should be encouraged to examine whether: (1) innovative treatments for early LD might prevent CLD, (2) early diagnosis of CLD might result in better treatment outcomes, and (3) more effective regimens can be developed for CLD patients who have had prolonged illness and an associated poor quality of life.

\section{References}

[1] N. A. Shadick, C. B. Phillips, E. L. Logigian, et al., "The longterm clinical outcomes of Lyme disease. A population-based retrospective cohort study," Annals of Internal Medicine, vol. 121, no. 8, pp. 560-567, 1994.

[2] E. S. Asch, D. I. Bujak, M. Weiss, M. G. E. Peterson, and A. Weinstein, "Lyme disease: an infectious and postinfectious syndrome," Journal of Rheumatology, vol. 21, no. 3, pp. 454461, 1994.

[3] M. S. Klempner, L. T. Hu, J. Evans, et al., "Two controlled trials of antibiotic treatment in patients with persistent symptoms and a history of Lyme disease," New England Journal of Medicine, vol. 345, no. 2, pp. 85-92, 2001.

[4] B. A. Fallon, J. G. Keilp, K. M. Corbera, et al., "A randomized, placebo-controlled trial of repeated IV antibiotic therapy for Lyme encephalopathy," Neurology, vol. 70, no. 13, pp. 9921003, 2008.

[5] L. B. Krupp, L. G. Hyman, R. Grimson, et al., "Study and treatment of post Lyme disease (STOP-LD): a randomized double masked clinical trial," Neurology, vol. 60, no. 12, pp. 1923-1930, 2003.

[6] M. S. Klempner, "Controlled trials of antibiotic treatment in patients with post-treatment chronic Lyme disease," Vector Borne and Zoonotic Diseases, vol. 2, no. 4, pp. 255-263, 2002.

[7] D. J. Cameron, "Clinical trials validate the severity of persistent Lyme disease symptoms," Medical Hypotheses, vol. 72, no. 2, pp. 153-156, 2009.

[8] X. Zhang, M. I. Meltzer, C. A. Pena, A. B. Hopkins, L. Wroth, and A. D. Fix, "Economic impact of Lyme disease," Emerging Infectious Diseases, vol. 12, no. 4, pp. 653-660, 2006.

[9] G. P. Wormser, R. J. Dattwyler, E. D. Shapiro, et al., "The clinical assessments treatment, and prevention of Lyme disease, human granulocytic anaplasmosis, and babesiosis: clinical practice guidelines by the Infectious Diseases Society of America," Clinical Infectious Diseases, vol. 43, no. 9, pp. 1089-1134, 2006.

[10] N. A. Shadick, C. B. Phillips, O. Sangha, et al., "Musculoskeletal and neurologic outcomes in patients with previously treated Lyme disease," Annals of Internal Medicine, vol. 131, no. 12, pp. 919-926, 1999.

[11] E. Hodzic, S. Feng, K. Holden, K. J. Freet, and S. W. Barthold, "Persistence of Borrelia burgdorferi following antibiotic treatment in mice," Antimicrobial Agents and Chemotherapy, vol. 52, no. 5, pp. 1728-1736, 2008.

[12] H. Yrjänäinen, J. Hytönen, K.-O. Söderström, J. Oksi, K. Hartiala, and M. K. Viljanen, "Persistent joint swelling and borrelia-specific antibodies in Borrelia garinii-infected mice after eradication of vegetative spirochetes with antibiotic treatment," Microbes and Infection, vol. 8, no. 8, pp. 20442051, 2006.

[13] J. J. Halperin, E. D. Shapiro, E. Logigian, et al., "Practice parameter: treatment of nervous system Lyme disease (an evidence-based review): report of the quality standards subcommittee of the American Academy of Neurology," Neurology, vol. 69, no. 1, pp. 91-102, 2007.

[14] G. P. Wormser, R. Ramanathan, J. Nowakowski, et al., "Duration of antibiotic therapy for early Lyme disease: a randomized, double-blind, placebo-controlled trial," Annals of Internal Medicine, vol. 138, no. 9, pp. 697-704, 2003.

[15] H. M. Feder Jr. and D. L. Whitaker, "Misdiagnosis of erythema migrans," American Journal of Medicine, vol. 99, no. 4, pp. 412419, 1995.

[16] M. C. Reid, R. T. Schoen, J. Evans, J. C. Rosenberg, and R. I. Horwitz, "The consequences of overdiagnosis and overtreatment of Lyme disease: an observational study," Annals of Internal Medicine, vol. 128, no. 5, pp. 354-362, 1998.

[17] M. Vrethem, L. Hellblom, M. Widlund, et al., "Chronic symptoms are common in patients with neuroborreliosis-a questionnaire follow-up study," Acta Neurologica Scandinavica, vol. 106, no. 4, pp. 205-208, 2002. 
[18] A. C. Steere, E. Taylor, G. L. McHugh, and E. L. Logigian, "The overdiagnosis of Lyme disease," Journal of the American Medical Association, vol. 269, no. 14, pp. 1812-1816, 1993.

[19] A. L. Hassett, D. C. Radvanski, S. Buyske, S. V. Savage, and L. H. Sigal, "Psychiatric comorbidity and other psychological factors in patients with "chronic Lyme disease", American Journal of Medicine, vol. 122, no. 9, pp. 843-850, 2009.

[20] D. J. Cameron, "Insufficient evidence to deny antibiotic treatment to chronic Lyme disease patients," Medical Hypotheses, vol. 72, no. 6, pp. 688-691, 2009.

[21] S. Silverman, E. M. Dukes, S. S. Johnston, N. A. Brandenburg, A. Sadosky, and D. M. Huse, "The economic burden of fibromyalgia: comparative analysis with rheumatoid arthritis," Current Medical Research and Opinion, vol. 25, no. 4, pp. 829840, 2009.

[22] A. E. Clarke, J. M. Esdaile, D. A. Bloch, D. Lacaille, D. S. Danoff, and J. F. Fries, "A Canadian study of the total medical costs for patients with systemic lupus erythematosus and the predictors of costs," Arthritis and Rheumatism, vol. 36, no. 11, pp. 1548-1559, 1993.

[23] G. D. Ebel, E. N. Campbell, H. K. Goethert, A. Spielman, and S. R. Telford III, "Enzootic transmission of deer tick virus in new England and Wisconsin sites," American Journal of Tropical Medicine and Hygiene, vol. 63, no. 1-2, pp. 36-42, 2000.

[24] http://www.ct.gov/ag/lib/ag/health/0129lyme.pdf, p. 290,2008.

[25] D. J. Cameron, "Generalizability in two clinical trials of Lyme disease," Epidemiologic Perspectives and Innovations, vol. 3, article 12, 2006.

[26] J. J. Halperin, "Prolonged Lyme disease treatment: enough is enough,” Neurology, vol. 70, no. 13, pp. 986-987, 2008.

[27] B. H. Skogman, S. Croner, M. Nordwall, M. Eknefelt, J. Ernerudh, and P. Forsberg, "Lyme neuroborreliosis in children: a prospective study of clinical features, prognosis, and outcome," Pediatric Infectious Disease Journal, vol. 27, no. 12, pp. 1089-1094, 2008.

[28] B. J. Bloom, P. M. Wyckoff, H. C. Meissner, and A. C. Steere, "Neurocognitive abnormalities in children after classic manifestations of Lyme disease," Pediatric Infectious Disease Journal, vol. 17, no. 3, pp. 189-196, 1998.

[29] M. Vázquez, S. S. Sparrow, and E. D. Shapiro, "Long-term neuropsychologic and health outcomes of children with facial nerve palsy attributable to Lyme disease," Pediatrics, vol. 112, no. 2, pp. e93-e97, 2003. 


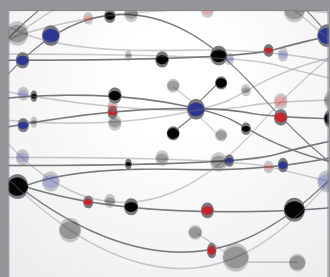

The Scientific World Journal
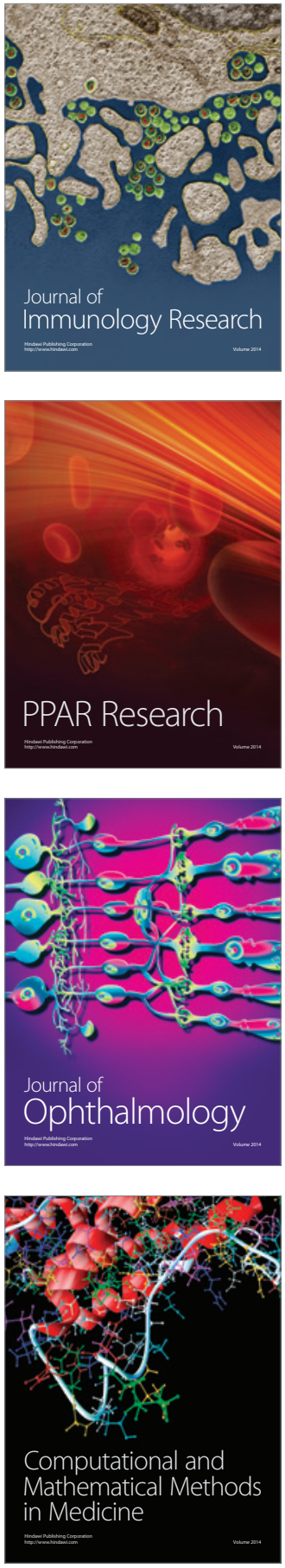

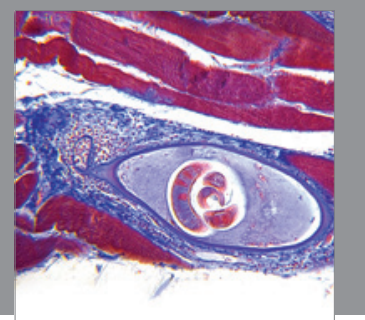

Gastroenterology

Research and Practice
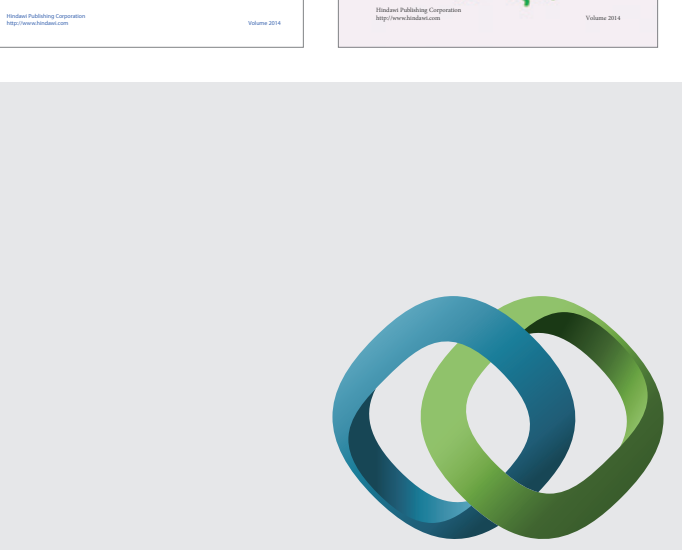

\section{Hindawi}

Submit your manuscripts at

http://www.hindawi.com
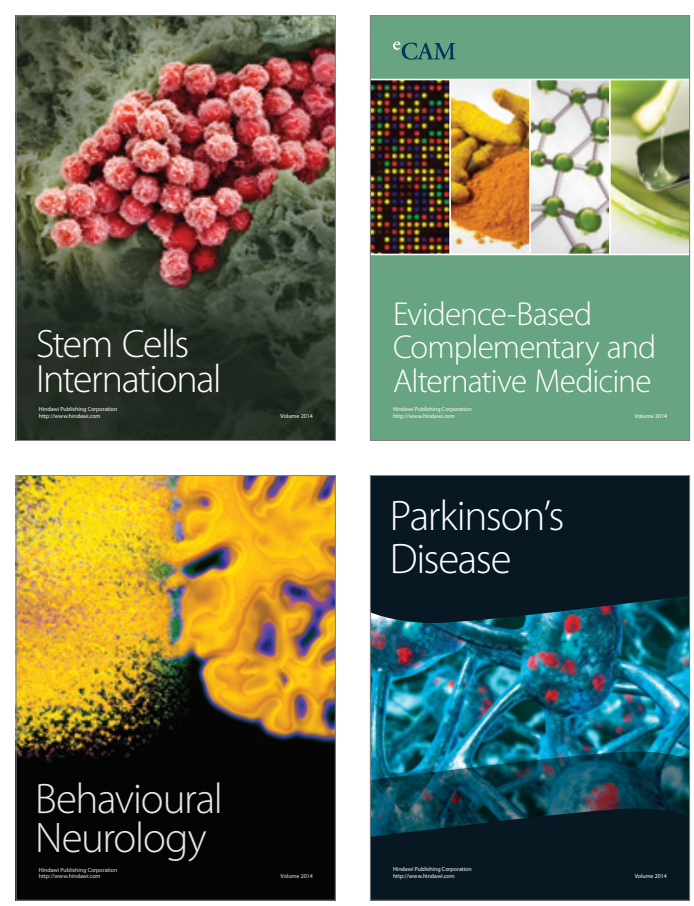

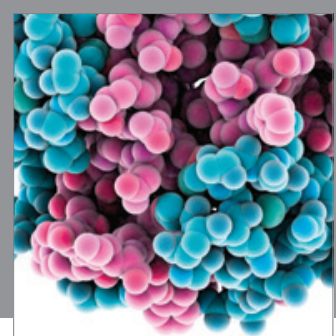

Journal of
Diabetes Research

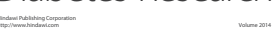

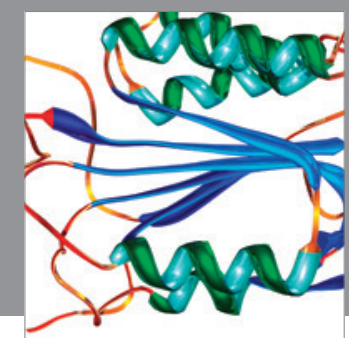

Disease Markers
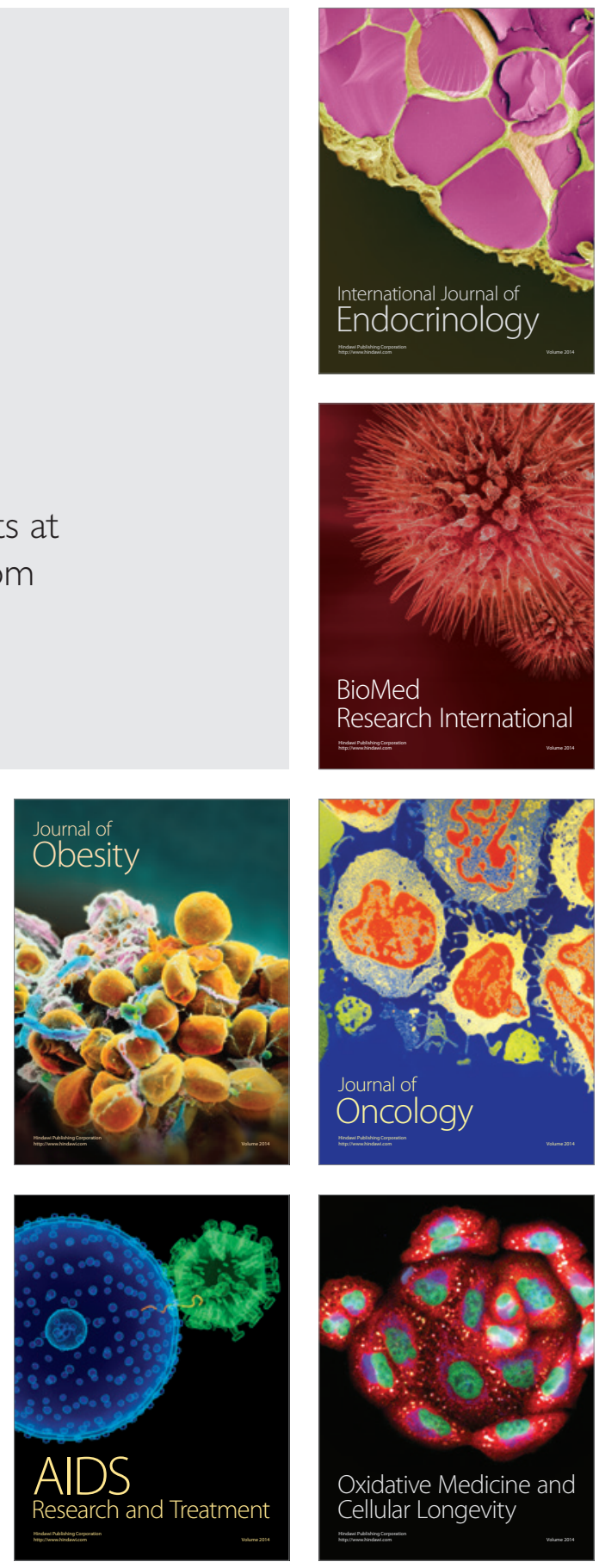